\title{
Afferent Control of Horizontal Cell Morphology Revealed by Genetic Respecification of Rods and Cones
}

\author{
Mary A. Raven, ${ }^{1}$ Edwin C. T. Oh, ${ }^{3,4}$ Anand Swaroop, ${ }^{3,4,5}$ and Benjamin E. Reese ${ }^{1,2}$ \\ ${ }^{1}$ Neuroscience Research Institute and ${ }^{2}$ Department of Psychology, University of California at Santa Barbara, Santa Barbara, California 93106, and ${ }^{3}$ Program \\ in Neuroscience and Departments of ${ }^{4}$ Ophthalmology and Visual Sciences and ${ }^{5}$ Human Genetics, University of Michigan, Ann Arbor, Michigan 48105
}

The first inhibitory interneurons of the retina, the horizontal cells, stratify within the outer plexiform layer, extending dendritic terminals that connect to the pedicles of cone photoreceptors and an axon terminal system contacting the spherules of rod photoreceptors. How the horizontal cells acquire this morphology is unknown, but instructive interactions with afferents are suggested to play a role in the development of synaptic circuits. Here, we show that the morphology of the axon terminal system and the dendritic field are selectively regulated by innervation from their respective afferents: genetic respecification of all cones to become rods, in $\mathrm{Crxp}$ - $\mathrm{Nrl}$ transgenic mice, produces an atrophic dendritic field yet leaves the axon terminal system largely intact. In contrast, in the retinas of $\mathrm{Nrl}^{-/-}$mice, in which the population of rod photoreceptors is respecified to adopt a cone fate, the dendritic field is hypertrophic, whereas the axon terminal system is underdeveloped. Our studies reveal that, although cell-intrinsic mechanisms drive the formation of independent dendritic versus axonal domains, the afferents play a selectively instructive role in defining their respective morphologies.

Key words: differentiation; cone pedicle; rod spherule; outer plexiform layer; $\mathrm{Nrl}$; axon terminal

\section{Introduction}

Horizontal cells in the mammalian retina give rise to dendrites that ramify in a radiate pattern within the outer plexiform layer $(\mathrm{OPL})$, in which their sole source of innervation is the terminals of cone photoreceptors, the pedicles (Kolb, 1974). One form of horizontal cell, being the only type present in the murine retina (Peichl et al., 1998), also extends an axonal-like process that courses for a short distance away from the dendritic field before elaborating a terminal arbor. Despite the similarity to axons elsewhere in the nervous system, the horizontal cell axon does not conduct nerve impulses but rather provides metabolic support for its terminal arbor, which is selectively innervated by the spherules of rod photoreceptors and serves as an independent functional entity comparable with the dendritic domain (Peichl et al., 1998). The dendritic and the axonal domains are not only postsynaptic to the cones and the rods, respectively, but also provide inhibitory feedback onto those photoreceptors through a currently debated mechanism (Kamermans et al., 2001; Hirasawa and Kaneko, 2003; Hirano et al., 2005). The molecular mechanisms generating this polarization of the cell into a dendritic and an axonal domain are unknown, but cell-intrinsic specification seems likely (Horton and Ehlers, 2003; Jan and Jan, 2003; Horton

Received Jan. 26, 2007; revised Feb. 21, 2007; accepted March 2, 2007.

This work was supported by National Institutes of Health Grants EY011087, EY011115, and EY007003, the Foundation Fighting Blindness, and Research to Prevent Blindness. We are grateful to Drs. Cheryl Craft, Xuemei Zhu, and the Mary D. Allen Laboratory in Vision Research, Doheny Eye Institute, University of Southern California (Los Angeles, (A) for the LUMlj antibody to mouse cone arrestin; and Dr. Wilko D. Altrock of the Leibniz Institute for Neurobiology (Magdeburg, Germany) for the antiserum to piccolo. We thank Alison Scott, Hadi Nassar, and Irene Whitney for technical assistance and Dr. Leo Peichl for comments on this manuscript.

Correspondence should be addressed to Benjamin E. Reese, Neuroscience Research Institute, University of California, Santa Barbara, CA 93106-5060. E-mail: breese@psych.ucsb.edu.

D0I:10.1523/JNEUROSCI.0372-07.2007

Copyright $\odot 2007$ Society for Neuroscience $\quad$ 0270-6474/07/273540-08\$15.00/0 et al., 2005). Afferent innervation may still, however, shape the differentiation of these cells, through secreted factors or by way of membrane-bound or activity-dependent signaling (McAllister, 2000; Cline, 2001; Lom et al., 2002; Wong and Ghosh, 2002; Hua and Smith, 2004; Sorensen and Rubel, 2006).

In the mouse retina, the afferent population of photoreceptors is composed of $97 \%$ rods and $3 \%$ cones (Carter-Dawson and LaVail, 1979b). We sought to define the role of the afferents by taking advantage of two different mouse models that genetically respecify the cones to adopt a rod fate or the rods to adopt a cone fate by manipulating the expression of the transcription factor gene $\mathrm{Nrl}$ (Swaroop et al., 1992). In $\mathrm{Crxp}-\mathrm{Nrl}$ transgenic mice (referred to herein as rod-full), the $\mathrm{Crx}$ promoter drives $\mathrm{Nrl} \mathrm{ex-}$ pression, instructing the postmitotic cone precursors to become rods; hence, cones are never formed (Oh et al., 2007). This transgenic mouse is distinct from a previously described cone-less mouse (Reese et al., 2005), in which the expression of an attenuated diphtheria toxin gene driven by a cone opsin promoter obliterates the cones during the first postnatal week (Soucy et al., 1998). The loss of $\mathrm{Nrl}$ in $\mathrm{Nrl}^{-/-}$mice (referred to herein as conefull), in contrast, causes all postmitotic rod precursors to become cones (Mears et al., 2001; Daniele et al., 2005). In this report, we first describe the general condition of the outer retina in these two mouse models, using immunofluorescence techniques to identify the organization of the OPL. We subsequently examine the morphology of individually labeled horizontal cell axons and dendrites to determine the extent to which their properties are dependent on the afferents.

\section{Materials and Methods}

Tissue preparation. All experiments were conducted in accord with the National Institutes of Health Guide for the Care and Use of Laboratory Animals and under authorization by respective Institutional Animal Care 

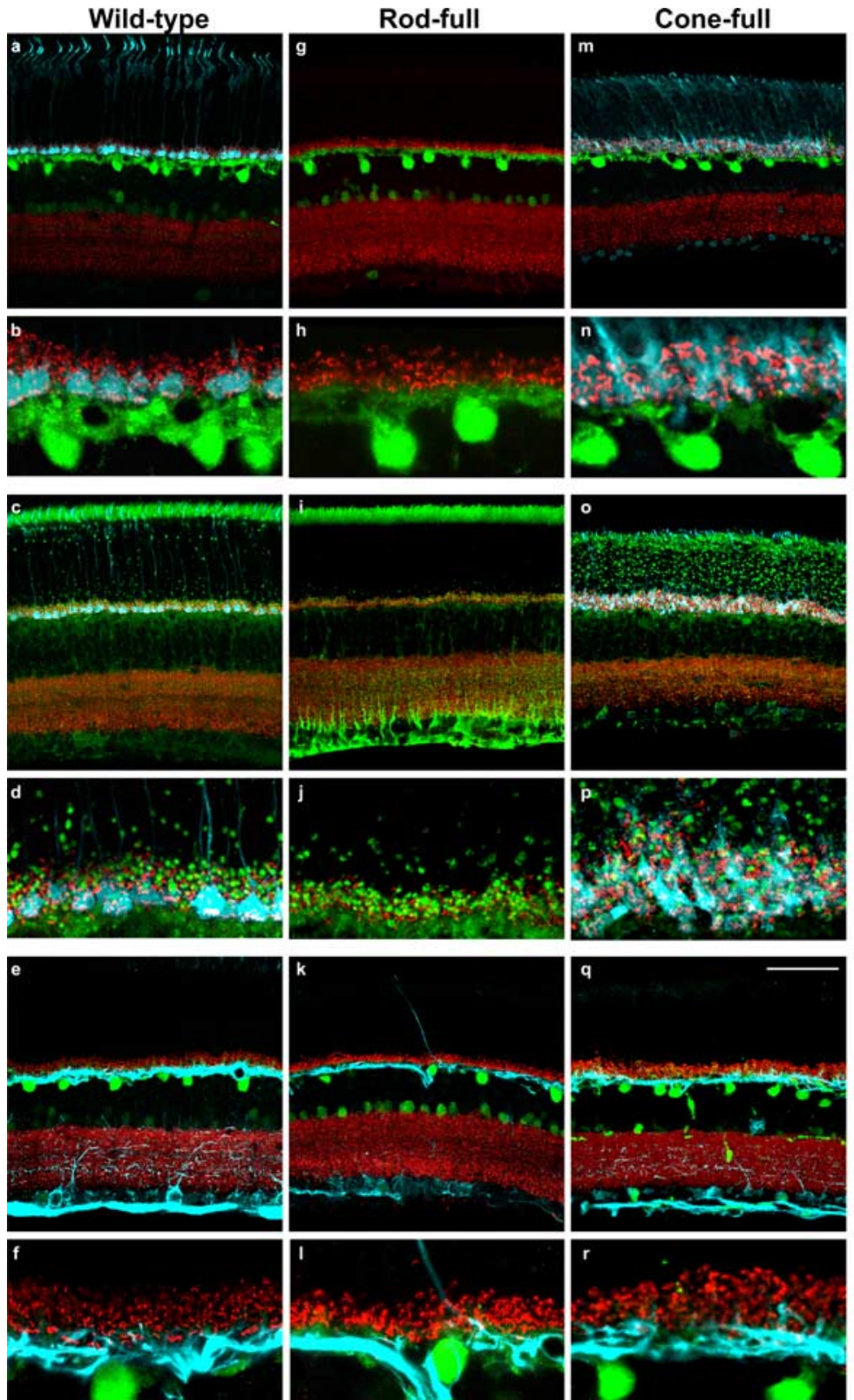

Figure 1. Vertical pairs of images from retinal sections at low and high magnification, from wild-type C57BL/6 mice (left) rod-full (Crxp-NrI) transgenic mice (middle), and cone-full ( $\mathrm{Nrl}^{-/-}$) mice (right). The higher-magnification images are centered on the OPL. Sections were immunolabeled for piccolo (red) to identify the ribbon synapses and to reveal the plexiform layers as a landmark. Sections in the top two-thirds of the figure $(\boldsymbol{a}-\boldsymbol{d}, \boldsymbol{g}-\boldsymbol{j}, \boldsymbol{m}-\boldsymbol{p})$ also show labeling for cone arrestin (blue), to identify the cone photoreceptor cells and their inner and outer segments, axons, and pedicles. Sections in the top $(\boldsymbol{a}, \boldsymbol{b}, \boldsymbol{g}, \boldsymbol{h}, \boldsymbol{m}, \boldsymbol{n})$ and bottom $(\boldsymbol{e}, \boldsymbol{f}, \boldsymbol{k}, \boldsymbol{l}, \boldsymbol{q}, \boldsymbol{r})$ thirds were also labeled for calbindin (green) to identify the horizontal cells and their dendritic plexus, whereas those in the middle third $(\boldsymbol{c}, \boldsymbol{d}, \boldsymbol{i}, \boldsymbol{j}, \mathbf{O}, \boldsymbol{p})$ were labeled for mitochondria using an antibody to cytochrome oxidase (green). Sections in the bottom third $(\boldsymbol{e}, \boldsymbol{f}, \boldsymbol{k}, \boldsymbol{l}, \boldsymbol{q}, \boldsymbol{r})$ were also labeled for neurofilaments (blue), to identify the axonal plexus. The sections from the cone-full $\left(\mathrm{Nrl}^{-/-}\right)$retinas were taken from peripheral retina, in which rosette-like distortions in the outer retinal architecture are minimal (Mears et al., 2001; Nikonov et al., 2005) and in which the retina is consequently thinner. Scale bar, $50 \mu \mathrm{m}$ for the low-magnification images and $14 \mu \mathrm{m}$ for the high-magnification images.

and Use Committees at the University of California at Santa Barbara and the University of Michigan. Wild-type C57BL/6 mice, rod-full (Crxp$\mathrm{Nrl}$ ) mice (Oh et al., 2007) and cone-full $\left(\mathrm{Nrl}^{-/-}\right)$mice (Mears et al., 2001) were given a lethal dose of sodium pentobarbital ( $120 \mathrm{mg} / \mathrm{kg}$, i.p.) and perfused with $0.9 \%$ saline followed by $4 \%$ paraformaldehyde in $0.1 \mathrm{M}$ sodium phosphate buffer, $\mathrm{pH} 7.2$ at $20^{\circ} \mathrm{C}$. Either whole retinas were dissected from the eyes or the entire eye was embedded in agarose and sectioned through the optic nerve head on a vibratome at a thickness of $100 \mu \mathrm{m}$. Retinal sections were prepared for immunofluorescence, whereas whole retinas were prepared for DiI labeling. cone arrestin piccolo cytochrome oxidase

Immunofluorescence. Retinal sections from 1-month-old mice were triple labeled using antibodies to calbindin (a mouse monoclonal antibody; 1:10,000; C8666; Sigma, St. Louis, MO), neurofilaments (a rabbit polyclonal antiserum to the $150 \mathrm{kDa}$ neurofilament subunit; 1:500; AB1981; Millipore, Temecula, CA), cytochrome oxidase (a mouse monoclonal antibody; 1:100; AB6403; Invitrogen, Eugene OR) piccolo [an affinity-purified guinea pig antibody; 1:1000 (Dick et al., 2001); a generous gift from W. Altrock, Leibniz Institute for Neurobiology, Magdeburg, Germany], and mouse cone arrestin [an affinity-purified rabbit antibody (LUMIj); 1:1000 (Zhu et al., 2002); a generous gift from C. Craft, University of Southern California, Los Angeles, CA]. Primary antibodies were detected with a mixture of appropriate donkey secondary IgGs conjugated to cyanine 2 (Cy2) or Alexa 488, Cy3, and Cy5 [1:200; Jackson ImmunoResearch (West Grove, PA) or Invitrogen]. Specimens were examined using an Olympus (Tokyo, Japan) Fluoview laserscanning confocal microscope with a $60 \times \mathrm{ob}$ jective, in which image stacks were collected at $1 \mu \mathrm{m}$ intervals across $10 \mu \mathrm{m}$.

DiI labeling. Crystals of the lipophilic dye DiI (D3911; Invitrogen) were inserted into fixed whole retinas from adult (2- to 4-month-old) mice and in postnatal day 5 (P5) and P10 mice, as described previously (Reese et al., 2005). Individual horizontal cell dendritic fields or axon terminals, labeled by diffusion through their axons, were subsequently imaged at $0.5 \mu \mathrm{m}$ intervals using confocal microscopy and reconstructed through their full three-dimensional extent using MetaMorph (Universal Imaging, Downingtown, PA) and AutoVisualize (Media Cybernetics, Silver Spring, MD). For adult labeled cells, the dendritic field area, the number of primary dendrites, and the depth of dendritic processes were determined using MetaMorph, as were the area and the depth of the axonal terminal fields. One-way ANOVAs were conducted, followed by post hoc Scheffé's tests to determine whether any of these morphological features differed among the adult wildtype, rod-full, and cone-full retinas. Additional details were provided previously (Reese et al., 2005).

\section{Results}

Reorganization of the outer retina in rod-full and cone-full mice

The characteristic features of the outer retina in the wild-type adult mouse are shown in Figure $1 a-d$ : an antibody to mouse cone arrestin, in blue, shows the cone outer segments at the top (Fig. 1a); beneath these, the cone inner segments and somata are labeled less intensely. The somata are restricted to this outermost portion of the outer nuclear layer (ONL), largely adjacent to the mitochondria-rich inner segments of the rods and cones, detected using an antibody to cytochrome oxidase, shown in green in Figure 1c. Each cone soma has a prominent mitochondrion situated basally (Carter-Dawson and LaVail, 1979a), at the location at which the axon emerges (Fig. 1c). Those axons extend 
through the full thickness of ONL, expanding to produce a stratum of pedicles within the OPL (Fig. 1a,c, blue profiles in the OPL). The presynaptic cytomatrix protein piccolo, present along the tip of synaptic ribbons in both pedicles and spherules (Dick et al., 2001), has also been labeled with an antibody, shown in red (Fig. $1 a-d$ ). Figure $1, b$ and $d$, is highermagnification views of the OPL, showing the localization of piccolo along the base of the pedicles, revealing the clustered distribution of the synaptic ribbons associated with each pedicle; the remaining piccolo labeling, largely outside or overlapping the apical aspect of the pedicles, identifies the distribution of the ribbon synapses associated with the rod spherules (unlabeled). The pedicles and spherules are also rich in mitochondria (Fig. 1d), although the mitochondria are more apically positioned relative to the ribbons, never colocalizing with the piccolo labeling (Carter-Dawson and LaVail, 1979a). Shown as well, in green in Figure $1 a$, is labeling for the calcium-binding protein, calbindin, a marker for horizontal cells and their processes, particularly their proximal dendrites. Because the plexus of horizontal cell dendrites is so dense and overlapping (Reese et al., 2005), the processes from individual horizontal cells cannot be resolved using immunostaining techniques. Notice the sites of contact between the calbindin-positive processes and the pedicles (Fig. 1b).

The architecture of the adult rod-full retina $(\mathrm{Crxp}-\mathrm{Nrl})$ is comparable with that of the wild-type retina, except that no cones are present (Fig. $1 g-j$ ). Labeled cone outer segments and somata are entirely absent (note the lack of blue profiles in Fig. $1 g, i)$, as is the stratum of perinuclear mitochondria in the outer parts of the ONL (Fig. 1 $i$; compare with green basal labeling in the blue somata in $c$ ), along with the stratum of pedicles within the OPL (Fig. $1 g-j$ ). Consistent with this absence of stratified cone pedicles, the pattern of piccolo immunostaining in the OPL is now devoid of an isolated stratum of clustered ribbons adjacent to the horizontal cell plexus (Fig. 1, compare $h, j, l$ with $b, d, f$ ). The calbindinpositive plexus of dendrites is still labeled in the rod-full retina, showing no overt changes relative to the wild-type retina (Fig. $1 \mathrm{~h}$, green label). The architecture of these rod-full retinas is similar to that of a cone-less transgenic mouse model in which nearly all (97\%) of the cone photoreceptors die during the early postnatal period after activation of an attenuated diphtheria toxin transgene driven by a cone opsin upstream regulatory sequence (Soucy et al., 1998; M.A.R. and B.E.R., unpublished observations).

The cone-full $\left(\mathrm{Nrl}^{-/-}\right)$retina, in contrast, shows cone somata labeled for mouse cone arrestin throughout the full thickness of the ONL (Fig. $1 m, n$ ) and large cytochrome oxidase-positive
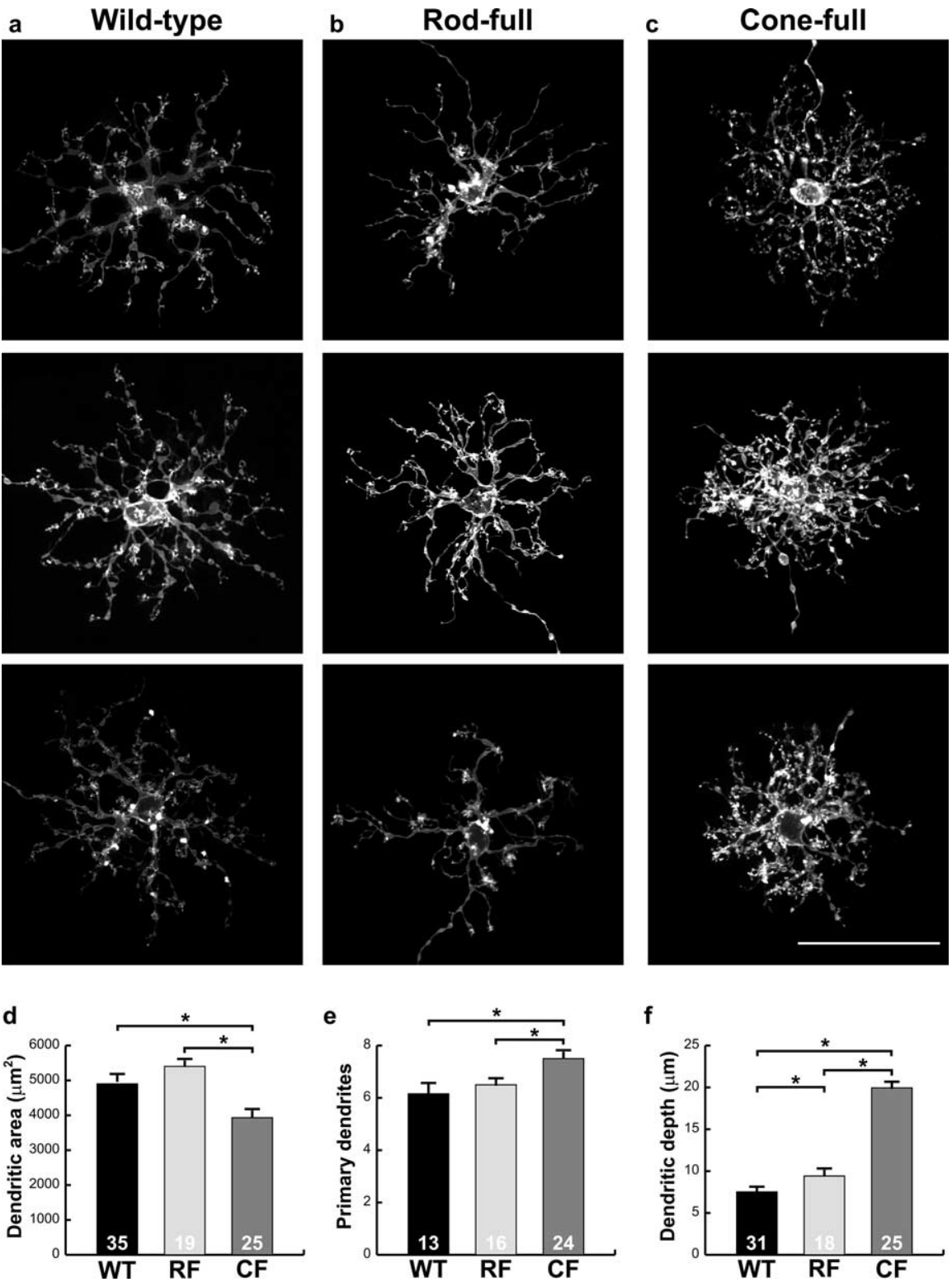

Figure 2. $\boldsymbol{a}-\boldsymbol{c}$, Examples of individual horizontal cells and their dendritic fields labeled with Dil in the mature wild-type (a) rod-full ( $\boldsymbol{b}$ ), and cone-full (c) retinas. The dendritic field is sparse and atrophic in the rod-full retina, whereas it is hypertrophic in the cone-full retina. Scale bar, $50 \mu \mathrm{m}$. $\boldsymbol{d}$-f , The dendritic field area is slightly smaller in the cone-full retina (d), and the number of primary dendrites is slightly greater $(\boldsymbol{e})$, whereas the thickness of the dendritic arbor is larger $(\boldsymbol{f})$. One horizontal cell from each broader distribution of dendritic terminals across the depth of the OPL in the cone-full retina. ${ }^{*} p<0.5$. Error bars represent SEM. CF, Cone-full; RF, rod-full; WT, wild type.

puncta throughout the ONL (Fig. $1 o, p$ ), consistent with other evidence indicating that the entire population of cells in the ONL has now adopted a cone fate (Mears et al., 2001; Daniele et al., 2005; Nikonov et al., 2005). Within the OPL, a single stratum of large cone pedicles is no longer detectable; cone arrestin labeling now fills the entire depth of the OPL, but discrete profiles are less readily discriminated (Fig. $1 m-p$ ). The piccolo labeling pattern within the OPL also lacks an isolated stratum of basally located, clustered ribbons adjacent to the horizontal cell plexus (Fig. 1n,p; compare with $b, d)$. These morphological changes are consistent with EM data showing a reorganization of the OPL, in which pedicle-like structures with multiple synaptic ribbons are present throughout the depth of the OPL, but that the ribbons within a pedicle are not stratified along the basal surface (Strettoi et al., 2004). 
P-5
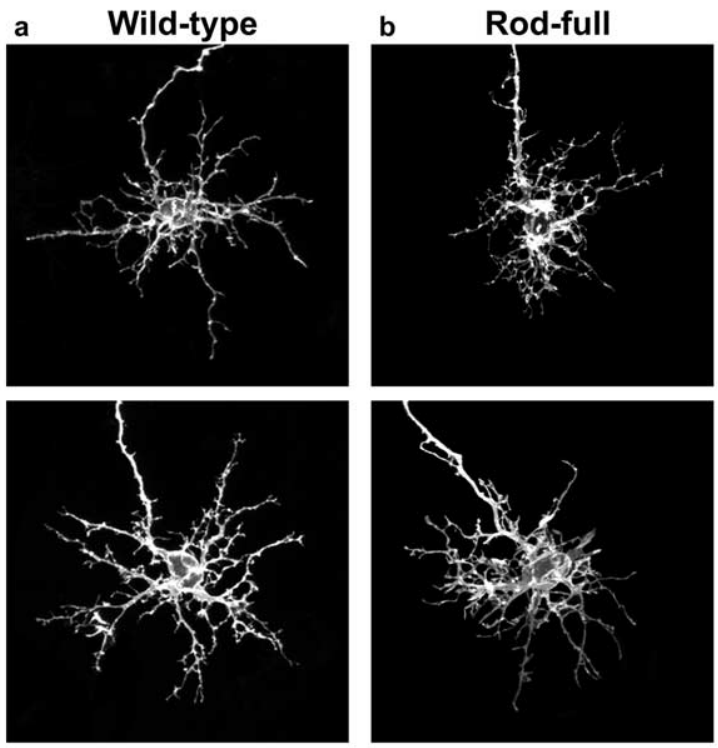

P-10

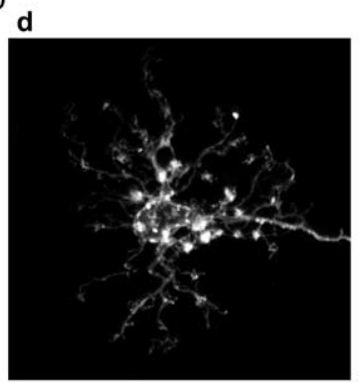

e
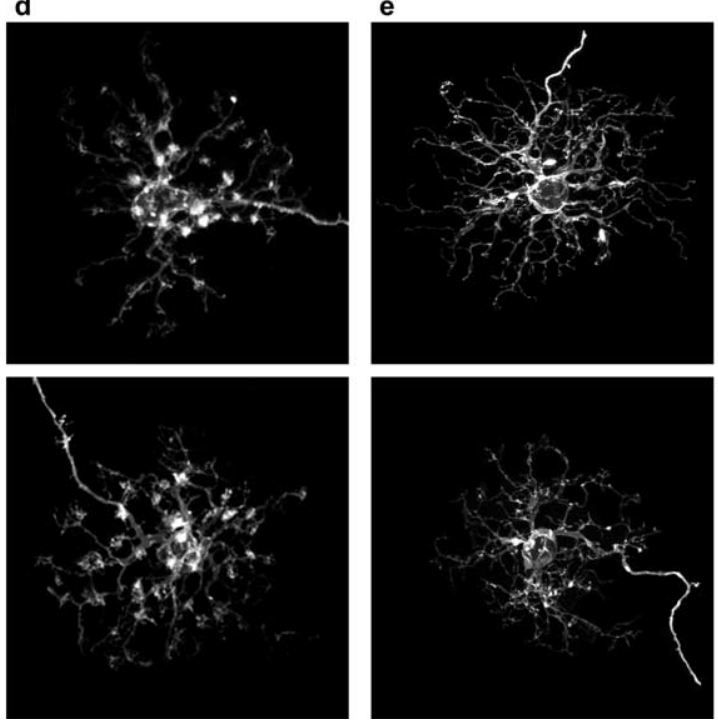
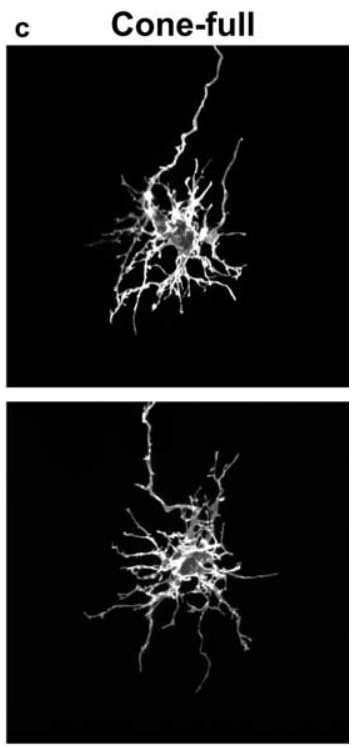

f
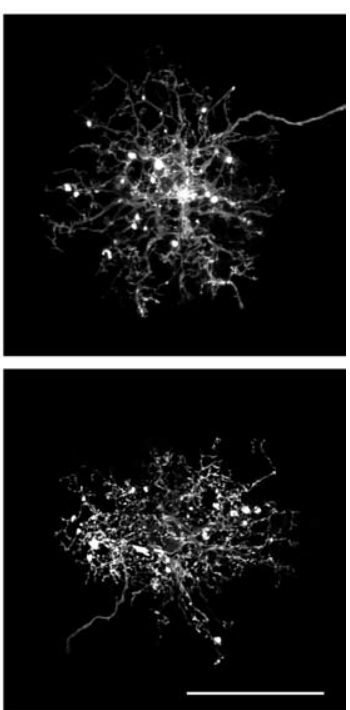

Figure 3. $\boldsymbol{a}-\boldsymbol{f}$, Developing dendritic fields in the wild-type $(\boldsymbol{a}, \boldsymbol{d})$, rod-full $(\boldsymbol{b}, \boldsymbol{e})$, and cone-full $(\boldsymbol{c}, \boldsymbol{f})$ retinas labeled with Dil at P5 $(\boldsymbol{a}-\boldsymbol{c})$ and P10 $(\boldsymbol{d}-\boldsymbol{f})$. Dendritic fields become discriminable only after P5, when synaptogenesis between the pedicles and horizontal cells takes place. Scale bar, $50 \mu \mathrm{m}$.

The axon of the horizontal cell is rich in neurofilaments (Peichl and Gonzalez-Soriano, 1993), and antibodies to the medium neurofilament subunit label processes within the OPL that do not, for the most part, colocalize with calbindin-labeled dendrites (Fig. 1e,f). Both are distributed within the OPL of the wildtype retina; however, the distal tips of the dendrites and the axon terminal system, at which these contact the pedicles and spherules, respectively, are less readily labeled (Fig. 1e,f). In the rod-full retina, the organization of the OPL in such immunolabeled specimens is not appreciably different, but for the presence of occasional sprouting by labeled processes into the ONL (Fig. $1 k, l$ ). The sprouting is most clearly revealed using antibodies to neurofilament (NF), but these processes are also occasionally calbindin-positive and cannot be unambiguously associated with either a dendritic or axonal component on the basis of their immunolabeling alone (Fig. $1 k, l$ ). Such sprouting is not detected in the cone-full $\left(\mathrm{Nrl}^{-/-}\right)$retina, in which the immunolabeling pat-

tern for NF is qualitatively like that seen in the wild-type retina (Fig. 1q,r).

\section{Dendritic morphology is regulated by} the cones

Horizontal cells give rise to, on average, six primary dendrites that extend from the soma to course within the OPL, branching to establish a dendritic field with an average diameter of $79 \mu \mathrm{m}$ (Fig. 2a). Higherorder branches give rise to periodic terminal clusters that contact individual pedicles within the dendritic field, and because of their overlapping dendritic coverage, about six neighboring horizontal cells contact each pedicle (Reese et al., 2005).

Horizontal cells in the rod-full retina, in contrast, show an atrophic dendritic morphology when compared with wildtype retina (Fig. $2 b$ ), yet dendritic field size is largely unchanged, being on average 78 $\mu \mathrm{m}$ in diameter. The periodic terminal clusters are absent, although small clusters are infrequently found within the field. The atrophic morphology of these cells is comparable with that observed in the retinas of cone-less transgenic mice, but the latter show conspicuously larger and dystrophic, if comparably rare, terminal clusters (Reese et al., 2005). The overall similarity in phenotype between these models demonstrates that the atrophy cannot reflect putative degenerative changes after denervation, because the horizontal cells in the rod-full retina are never exposed to cone pedicles during development.

Horizontal cells in the cone-full retina have an average of eight primary dendrites and establish a dendritic field that is slightly smaller than that in the wild-type or cone-less retinas, averaging $71 \mu \mathrm{m}$ in diameter (Fig. 2d,e). More conspicuously, the density of higher-order branching within the dendritic field is far greater in the cone-full retina (Fig. $2 c$ ). Within that dense dendritic field, individual terminal clusters associated with single pedicles are not discriminable when compared with wild-type horizontal cells, because of the density of pedicles within the OPL. Consistent with this, labeled dendritic fields, when viewed in rotation (see supplemental movie 1, available at www.jneurosci.org as supplemental material), now occupy the full depth of the OPL rather than arborizing only within the innermost portion of this synapse-rich region, in which their synaptic contacts with pedicles are normally found (compare with Fig. 1b,n). Dendritic arborization depth was significantly greater in these cone-full retinas (Fig. $2 f$ ).

These features discriminating the dendritic field of horizontal cells in wild-type, rod-full, and cone-full retinas emerge after the normal period of synaptogenesis with the cone pedicles, beginning at P5. Before this stage, the dendrites of horizontal cells radiate in multiple directions from the soma. On $\mathrm{P} 5$, they begin to stratify in the nascent OPL, although periodic terminal clusters have yet to form (Reese et al., 2005). Horizontal cells in the wild- 
type, rod-full, and cone-full retinas are barely discriminable at this initial stage of stratification (Fig. $3 a-c$ ). By P10, however, the wild-type cells display periodic clusters studded across the stratified dendritic field, associated with the sites of pedicle contact (Fig. 3d), whereas those in the rod-full retina show no evidence of terminal clustering (Fig. 3e), well after they have stratified within a cone-free environment. Rather, in the absence of pedicles, the dendritic fields of horizontal cells in the rod-full retina exhibit hypertrophic branching (Fig. 3e), as they do in the cone-less transgenic retina at this stage (Reese et al., 2005). The dendritic fields of $\mathrm{P} 10$ horizontal cells in the cone-full retina are also hypertrophic (Fig. 3f), maintaining this excessive branching into maturity (Fig. 2c), whereas the horizontal cells deprived of any cone afferents subsequently atrophy (Fig. 2b).

\section{Axonal morphology is regulated by the rods}

The axon terminal and its appendages, forming contacts exclusively with rod spherules, has a more variable size, shape, and orientation (Fig. 4a). The axon broadens to form the thicker body of the terminal, giving rise to multiple branches, which in turn yield individual branchlets extending into the spherules, with two to four per spherule in association with the one to two ribbons made by each spherule (Migdale et al., 2003). In the rod-full retina, the morphology of single axon terminals appears expanded in size, although not significantly (Fig. $4 b, d$ ). Cone-full retinas, in contrast, having no rod photoreceptors, display an axon terminal arbor that is comparably atrophic: although the primary branch of the axon terminal is present, the higher-order branchlets that characterize the wild-type and rodfull terminal field are often reduced in density in the cone-full retina (Fig. 4c). Associated with this, the overall area of the axon terminal field is smaller (Fig. $4 d$ ), although the depth of its distribution is greater (Fig. 4e), spanning the thickness of the expanded OPL (Fig. 1n,p,r; see supplemental movie 2, available at www.jneurosci.org as supplemental material).

The rod spherules normally establish synaptic contacts after the cone pedicles initiate synaptogenesis (Olney, 1968; Blanks et al., 1974; Sherry et al., 2003). Curiously, changes in the axon terminals can be detected as early as P5, when both the developing arbor and the girth of the axonal process itself are reduced relative to those axonal arbors for wild-type and rod-full retinas (Fig. 5). In the absence of any rods, their growth would appear to be stunted even at this early stage, but they go on to develop a morphology similar to that of a wild-type axon terminal arbor, albeit reduced in area and expanded in depth (Fig. 4).
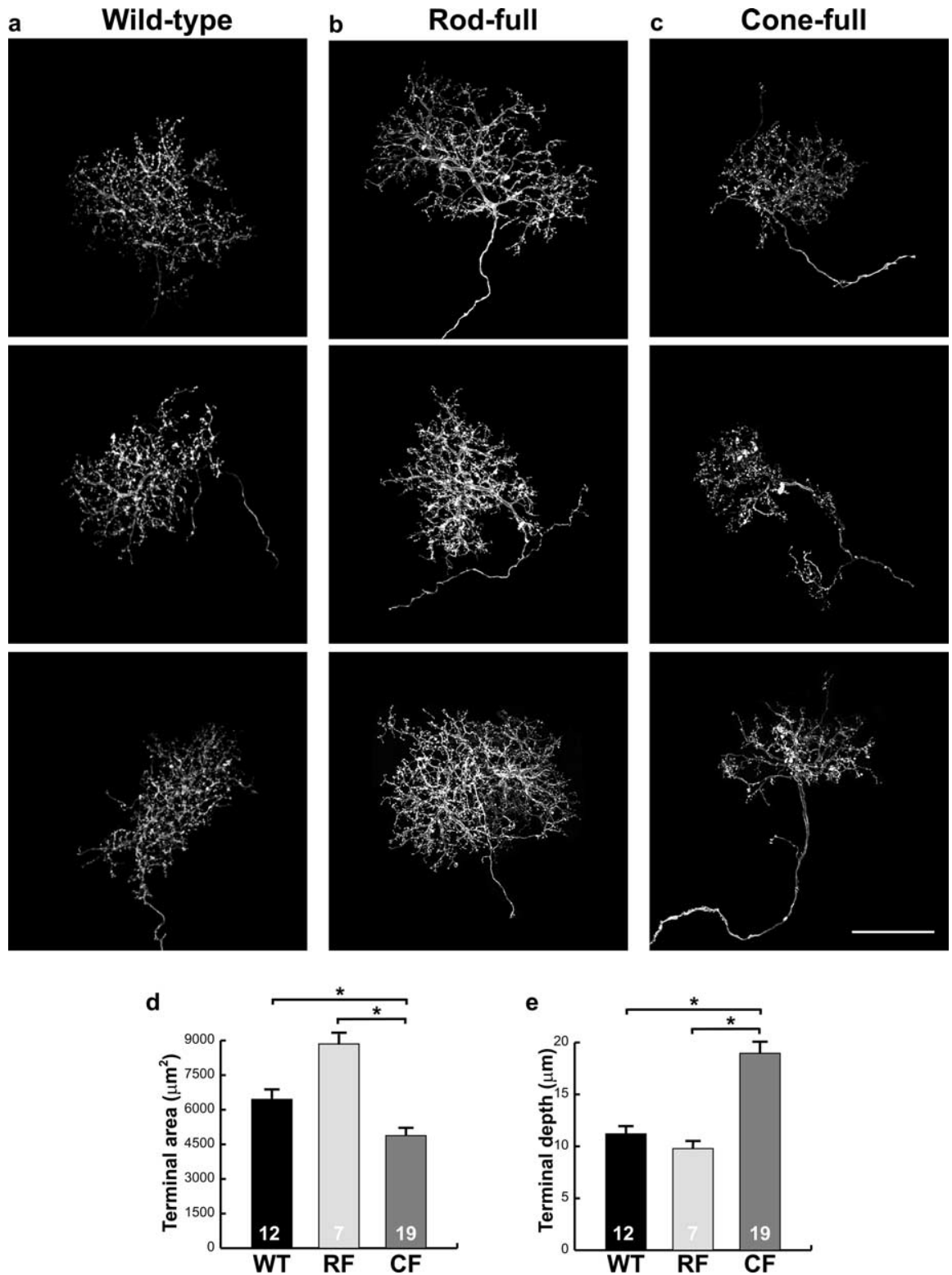

Figure 4. $\boldsymbol{a}-\boldsymbol{c}$, Individual horizontal cell axon terminals labeled with Dil in the wild-type (a), rod-full (b), and cone-full (c) etinas. The terminal field is dense in the wild-type and rod-full retinas, whereas it is relatively atrophic in the cone-full retina. Scale One of each of these terminals is shown in rotation in supplemental movie 2 (available at www.jneurosci.org as supplementa material), further revealing the atrophic condition of the terminal field in the absence of the rods. ${ }^{*} p<0.5$. Error bars represent SEM. CF, Cone-full; RF, rod-full; WT, wild type.

\section{Discussion}

The establishment of neuronal architecture within the CNS is a complex developmental process that is as yet poorly elucidated. The lesser complexity and ready access to the neural retina render it an ideal system for dissecting the underlying mechanisms that generate synaptic connectivity and cellular architecture using genetically manipulated mouse models. In this report, we show that the distinct properties of the dendritic and the axonal arbors of horizontal cells are independently controlled by their afferents during development. The periodic distribution of cone pedicles instructs a comparably periodic formation of terminal clusters in the wild-type retina. In strains of mice with a $50 \%$ reduction in cone afferents, the frequency of such terminal clustering is coincidently reduced (Reese et al., 2005), whereas a complete elimi- 
P-5
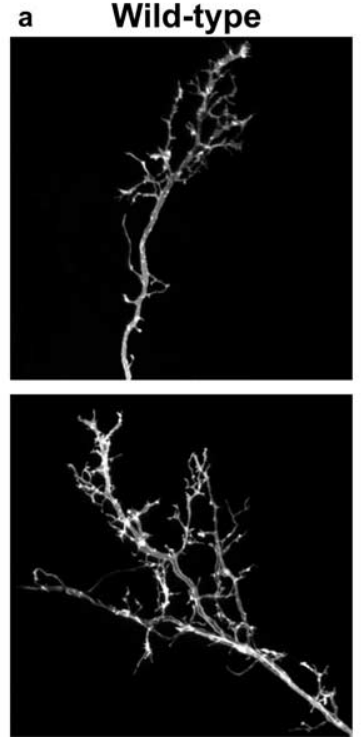

b
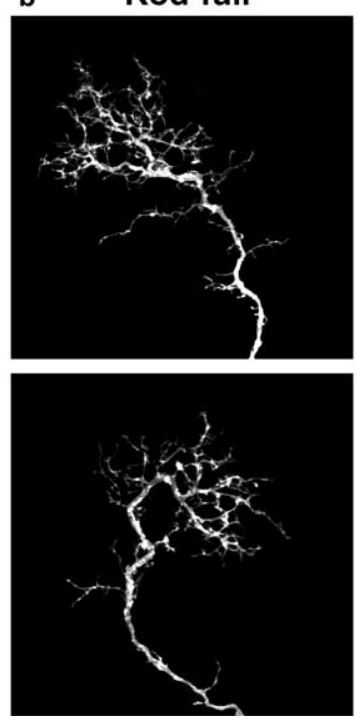

Figure 5. $\boldsymbol{a}-\boldsymbol{c}$, Developing axonal arbors in the wild-type $(\boldsymbol{a})$, rod-full $(\boldsymbol{b})$, and cone-full $(\boldsymbol{c})$ retinas labeled with Dil at P5. Even at this early stage, before synaptogenesis between the spherules and axonal arbor, the girth of the axon and the size of the developing terminal are reduced in the cone-full retina. Scale bar, $50 \mu \mathrm{m}$

nation of cone afferents in the rod-full retina leads to a failure of these clustered terminals to form. Conversely, the large increase in cone afferents in the cone-full retina induces a blanket of dendritic terminals to form, no longer showing any periodicity nor stratification in their formation, extending to fill the depth of the OPL. Together, these results make clear that the cone afferents play an instructive, rather than merely a permissive, role in defining the dendritic morphology of a horizontal cell.

The dense distribution of rod spherules present in the wildtype retina, differentiating slightly later than the cone pedicles (Olney, 1968; Blanks et al., 1974), acts independently on the axon terminal system, inducing a comparably dense branching and terminal sprouting to form. Respecification of the cones to become rods appears to yield a larger axonal arbor, whereas the entire loss of the rods in the cone-full retina yields an underdeveloped axon terminal field, although those changes do not appear to be proportional to the size of the afferent population. The stunted development of the axon terminal system in the cone-full retina is apparent even before synaptogenesis, suggesting that differentiating rods are already supplying a signal for axon terminal outgrowth during normal development. Together, these results demonstrate how different afferent populations regulate the morphology of a nerve cell. Although horizontal cell morphology is unique in having discrete compartments as synaptic targets, nerve cells throughout the CNS exhibit regional specificity in the distribution of their afferents on the cell surface and may in turn prove to differentiate those select portions of the postsynaptic cell under the instructive effects of those afferents.

The selective responsiveness of these two compartments of the horizontal cell cannot be explained by the effects of regionally distinct signals, because the axon terminals and the dendritic arbors of neighboring horizontal cells overlap one another within the OPL. Despite their overlapping distributions, they must recognize one another as distinct entities, because each forms gap junctional contacts exclusively with their homotypic partners (He et al., 2000). Although there is a slight temporal delay be-
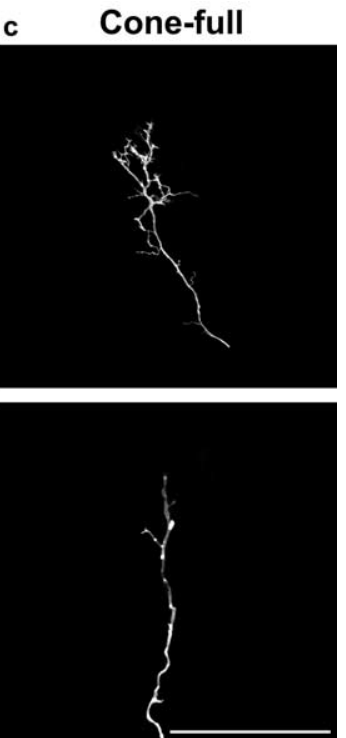

tween the maturation of cone pedicles and rod spherules, both the dendritic arbor and a discriminable axon are already present by the time of synaptogenesis (Raven et al., 2005), and so each must be exposed to the same local environment within the developing OPL. Instead, our results suggest that cell-intrinsic mechanisms establish a polarization of the neuron, trafficking proteins to each compartment that constrain their subsequent development and render them sensitive to distinct instructive signals. The fact that horizontal cell dendrites become hypertrophic at $\mathrm{P} 10$ in the rod-full retina, much like they do in the cone-less retina (Reese et al., 2005), suggests that, although this cellular compartment is instructively regulated by afferent density, there is an intrinsic component to this developmental process as well, as though the horizontal cells are programmed to seek out afferent innervation. Failing to find it, they undergo regression, whereas finding normal or excessive densities of cone afferents, they branch accordingly to innervate all of the pedicles within their dendritic fields.

Our data, showing how the local retinal environment regulates neuronal morphology, run counter to recent publications favoring a cell-autonomous specification of morphological differentiation. For example, Math $5^{-/-}$and $\mathrm{Brn} 3 \mathrm{~b}^{-/-}$mice contain reduced numbers of retinal ganglion cells that still develop a normal dendritic morphology (Lin et al., 2004), even in the presence of excessive amacrine cells (Wang et al., 2001). Cholinergic amacrine cells likewise develop a normal dendritic arbor despite reductions in the local density of homotypic cells as well as other cell types (Farajian et al., 2004). In comparison, the horizontal cells would appear to be sensitive to both their afferents (present data) and their homotypic neighbors, given the reciprocal relationship between dendritic field size and horizontal cell density across different strains of mice (Reese et al., 2005). Somewhat surprisingly, the horizontal cells of the cone-full retinas had smaller dendritic fields, indicating that field size is not exclusively controlled by proximity to homotypic neighbors. The expansion of cellular volume associated with this degree of dendritic branching may come at a cost to the overall dendritic field extent, reducing slightly dendritic coverage.

The present results are also unexpected given the recent demonstration that the primary target of the rod spherules, the rod bipolar cells, do not fail to differentiate their dendrites in the absence of rods in the $\mathrm{Nrl}^{-/-}$retina. Rather, they become innervated by the respecified population of cone photoreceptors (Strettoi et al., 2004). Rod bipolar cells do not differentiate normally in the $r d 1$ retina, in which the rod and cone photoreceptor populations die postnatally, indicating that they do require an afferent population to form (Strettoi and Pignatelli, 2000). Our data suggest that, although the central postsynaptic elements at the ribbons of such respecified cones may now include rod bipolar dendrites (Strettoi et al., 2004), many of the lateral postsynaptic elements should be the dendritic terminals of horizontal cells, indicating that the recruitment of the rod pathway in this mouse model may be only a partial one. That the axon terminal arbor is not entirely atrophic in these cone-full retinas reveals some in- 
trinsic capacity to differentiate; as these terminals extend throughout a thicker OPL in such retinas, but do not exhibit conspicuous sprouting into the ONL (present results; Oh et al., 2007), they are also likely to form synaptic contacts with the respecified cones.

The developmental plasticity associated with horizontal cell morphology described in the present study is distinct from recent descriptions of horizontal cell sprouting in rodent models of retinal degeneration. Disrupted gene function, affecting either phototransduction in the outer segment (Park et al., 2001; Strettoi et al., 2002; Claes et al., 2004; Cuenca et al., 2004) or neurotransmission within the outer plexiform layer (Mansergh et al., 2005; Chang et al., 2006), can lead to an outgrowth of ectopic horizontal cell processes into the inner and/or outer nuclear layers. This sprouting appears to be relatively slow, progressive, and in some cases reactive, indicating the cellular response to maintain normal morphology or function in degenerating retina (Lewis et al., 1998; Fariss et al., 2000; Jones et al., 2003). In this report, the present mouse models primarily reveal the cellular determinants for attaining appropriate neuronal morphology during synaptogenesis.

\section{References}

Blanks JC, Adinolfi AM, Lolley RN (1974) Synaptogenesis in the photoreceptor terminal of the mouse retina. J Comp Neurol 156:81-93.

Carter-Dawson LD, LaVail MM (1979a) Rods and cones in the mouse retina. I. Structural analysis using light and electron microscopy. J Comp Neurol 188:245-262.

Carter-Dawson LD, LaVail MM (1979b) Rods and cones in the mouse retina. II. Autoradiographic analysis of cell generation using tritiated thymidine. J Comp Neurol 188:263-272.

Chang B, Heckenlively JR, Bayley PR, Brecha NC, Davisson MT, Hawes NL, Hirano AA, Hurd RE, Ikeda A, Johnson BA, McCall MA, Morgans CW, Nusinowitz S, Peachey NS, Rice DS, Vessey KA, Gregg RG (2006) The nob2 mouse, a null mutation in Cacnalf: anatomical and functional abnormalities in the outer retina and their consequences on ganglion cell visual responses. Vis Neurosci 23:11-24.

Claes E, Seeliger M, Michalakis S, Biel M, Humphries P, Haverkamp S (2004) Morphological characterization of the retina of the CNGA3(-/-) $\mathrm{Rho}(-/-)$ mutant mouse lacking functional cones and rods. Invest Ophthalmol Vis Sci 45:2039-2048.

Cline HT (2001) Dendritic arbor development and synaptogenesis. Curr Opin Neurobiol 11:118-126.

Cuenca N, Pinilla I, Sauvé Y, Lu B, Wang S, Lund RD (2004) Regressive and reactive changes in the connectivity patterns of rod and cone pathways of P23H transgenic rat retina. Neuroscience 127:301-317.

Daniele LL, Lillo C, Lyubarsky AL, Nikonov SS, Philp N, Mears AJ, Swaroop A, Williams DS, Pugh EN (2005) Cone-like morphological, molecular, and electrophysiological features of the photoreceptors of the $\mathrm{Nrl}$ knockout mouse. Invest Ophthalmol Vis Sci 46:2156-2167.

Dick O, Hack I, Altrock WD, Garner CC, Gundelfinger ED, Brandstätter JH (2001) Localization of the presynaptic cytomatrix protein Piccolo at ribbon and conventional synapses in the rat retina: comparison with Bassoon. J Comp Neurol 439:224-234.

Farajian R, Raven MA, Cusato K, Reese BE (2004) Cellular positioning and dendritic field size of cholinergic amacrine cells are impervious to early ablation of neighboring cells in the mouse retina. Vis Neurosci 21:13-22.

Fariss RN, Li Z-Y, Milam AH (2000) Abnormalities in rod photoreceptors, amacrine cells, and horizontal cells in human retinas with retinitis pigmentosa. Am J Ophthalmol 129:215-223.

He S, Weiler R, Vaney DI (2000) Endogenous dopaminergic regulation of horizontal cell coupling in the mammalian retina. J Comp Neurol 418:33-40.

Hirano AA, Brandstätter JH, Brecha NC (2005) Cellular distribution and subcellular localization of molecular components of vesicular transmitter release in horizontal cells of rabbit retina. J Comp Neurol 448:70-81.

Hirasawa H, Kaneko A (2003) pH changes in the invaginating synaptic cleft mediate feedback from horizontal cells to cone photoreceptors by modulating $\mathrm{Ca}^{2+}$ channels. J Gen Physiol 122:657-671.
Horton AC, Ehlers MD (2003) Neuronal polarity and trafficking. Neuron 40:277-295.

Horton AC, Rácz B, Monson EE, Lin AL, Weinberg RJ, Ehlers MD (2005) Polarized secretory trafficking directs cargo for asymmetric dendrite growth and morphogenesis. Neuron 48:757-771.

Hua JY, Smith SJ (2004) Neural activity and the dynamics of central nervous system development. Nat Neurosci 7:327-332.

Jan Y-N, Jan LY (2003) The control of dendrite development. Neuron 40:229-242.

Jones BW, Watt CB, Frederick JM, Baehr W, Chen CK, Levine EM, Milam AH, Lavail MM, Marc RE (2003) Retinal remodeling triggered by photoreceptor degenerations. J Comp Neurol 464:1-16.

Kamermans M, Fahrenfort I, Schultz K, Janssen-Bienhold U, Sjoerdsma T, Weiler R (2001) Hemichannel-mediated inhibition in the outer retina. Science 292:1178-1180.

Kolb H (1974) The connections between horizontal cells and photoreceptors in the retina of the cat: electron microscopy of Golgi preparations. J Comp Neurol 155:1-14.

Lewis GP, Linberg KA, Fisher SK (1998) Neurite outgrowth from bipolar and horizontal cells after experimental retinal detachment. Invest Ophthalmol Vis Sci 39:424-434.

Lin B, Wang SW, Masland RH (2004) Retinal ganglion cell type, size, and spacing can be specified independent of homotypic dendritic contacts. Neuron 43:475-485.

Lom B, Cogen J, Sanchez AL, Vu T, Cohen-Cory S (2002) Local and targetderived brain-derived neurotrophic factor exert opposing effects on the dendritic arborization of retinal ganglion cells in vivo. J Neurosci 22:7639-7649.

Mansergh F, Orton NC, Vessey JP, Lalonde MR, Stell WK, Tremblay F, Barnes S, Rancourt DE, Bech-Hansen NT (2005) Mutation of the calcium channel gene Cacnalf disrupts calcium signaling, synaptic transmission and cellular organization in mouse retina. Hum Mol Gen 14:3035-3046.

McAllister AK (2000) Cellular and molecular mechanisms of dendrite growth. Cereb Cortex 10:963-973.

Mears AJ, Kondo M, Swain PK, Takada Y, Bush RA, Saunders TL, Sieving PA, Swaroop A (2001) Nrl is required for rod photoreceptor development. Nat Genet 29:447-452.

Migdale K, Herr S, Klug K, Ahmad K, Linberg K, Sterling P, Schein S (2003) Two ribbon synaptic units in rod photoreceptors of macaque, human, and cat. J Comp Neurol 455:100-112.

Nikonov SS, Daniele LL, Zhu X, Craft CM, Swaroop A, Pugh EN (2005) Photoreceptors of $\mathrm{Nrl}-/-$ mice coexpress functional S- and M-cone opsins having distinct inactivation mechanisms. J Gen Physiol 125:287-304.

Oh ECT, Khan N, Novelli E, Khanna H, Strettoi E, Swaroop A (2007) Transformation of cone precursors to functional rod photoreceptors by bZIP transcription factor NRL. Proc Natl Acad Sci 104:1679-1684.

Olney JW (1968) An electron microscopic study of synapse formation, receptor outer segment development, and other aspects of developing mouse retina. Invest Ophthalmol 7:250-268.

Park S-J, Kim I-B, Choi K-R, Moon J-I, Oh S-J, Chung J-W, Chun M-H (2001) Reorganization of horizontal cell processes in the developing FVB/N mouse retina. Cell Tissue Res 306:341-346.

Peichl L, Gonzalez-Soriano J (1993) Unexpected presence of neurofilaments in axon-bearing horizontal cells of the mammalian retina. J Neurosci 13:4091-4100.

Peichl L, Sandmann D, Boycott BB (1998) Comparative anatomy and function of mammalian horizontal cells. In: Development and organization of the retina. (Chalupa LM, Finlay BL, eds). New York: Plenum.

Raven MA, Stagg SB, Nassar H, Reese BE (2005) Developmental improvement in the regularity and packing of mouse horizontal cells: implications for mechanisms underlying mosaic pattern formation. Vis Neurosci 22:569-573.

Reese BE, Raven MA, Stagg SB (2005) Afferents and homotypic neighbors regulate horizontal cell morphology, connectivity, and retinal coverage. J Neurosci 25:2167-2175.

Sherry DM, Wang MM, Bates J, Frishman LJ (2003) Expression of vesicular glutamate transporter 1 in the mouse retina reveals temporal ordering in development of rod vs. cone and ON vs. OFF circuits. J Comp Neurol 465:480-498

Sorensen SA, Rubel EW (2006) The level and integrity of synaptic input regulates dendritic structure. J Neurosci 26:1539-1550. 
Soucy E, Wang Y, Nirenberg S, Nathans J, Meister M (1998) A novel signaling pathway from rod photoreceptors to ganglion cells in mammalian retina. Neuron 21:481-493.

Strettoi E, Pignatelli V (2000) Modifications of retinal neurons in a mouse model of retinitis pigmentosa. Proc Natl Acad Sci USA 97:11021-11025.

Strettoi E, Porciatti V, Falsini B, Pignatelli V, Rossi C (2002) Morphological and functional abnormalities in the inner retina of the $\mathrm{rd} / \mathrm{rd}$ mouse. J Comp Neurol 22:5492-5504.

Strettoi E, Mears AJ, Swaroop A (2004) Recruitment of the rod pathway by cones in the absence of rods. J Neurosci 24:7576-7582.
Swaroop A, Xu JZ, Pawar H, Jackson A, Skolnick C, Agarwal N (1992) A conserved retina-specific gene encodes a basic motif/leucine zipper domain. Proc Natl Acad Sci 89:266-270.

Wang SW, Kim BS, Ding K, Wang H, Sun D, Johnson RL, Klein WH, Gan L (2001) Requirement for math5 in the development of retinal ganglion cells. Genes Dev 15:24-29.

Wong ROL, Ghosh A (2002) Activity-dependent regulation of dendritic growth and patterning. Nat Rev Neurosci 3:803-812.

Zhu X, Li A, Brown B, Weiss ER, Osawa S, Craft CM (2002) Mouse cone arrestin expression pattern: light induced translocation in cone photoreceptors. Mol Vis 11:462-471. 